\title{
Achieving guideline-based asthma control: does the patient benefit?
}

\author{
E.D. Bateman*, L.F. Frith\#, G.L. Braunstein"
}

\begin{abstract}
Achieving guideline-based asthma control: does the patient benefit? E.D. Bateman, L.F. Frith, G.L. Braunstein. (C)ERS Journals Ltd 2002.

ABSTRACT: Asthma management guidelines define asthma control, but the outcome criteria used do not include the patient's own assessment of their health. The objective of the present study was to determine the association between the achievement of asthma control, as defined by the Global Initiative for Asthma (GINA) guidelines, and patient-assessed asthma-related quality of life (QOL), particularly whether maximal or near-maximal QOL scores were attainable.

Clinical data from three studies that compared salmeterol/fluticasone propionate combination therapy (SFC) with other treatments in patients with persistent asthma were retrospectively analysed. Achievement of asthma control was determined over an 8-week period in each study according to six parameters derived from the GINA guideline treatment goals. Asthma Quality of Life Questionnaire (AQLQ) scores (a 7 -point scale, where $1=$ severe impairment and $7=$ no impairment) were analysed by treatment group for well-controlled and not well-controlled patients.

The analysis showed that, across a range of severities, well-controlled asthma patients had consistently higher AQLQ scores at endpoint and larger AQLQ improvements from baseline, than patients who were not well controlled. For many well-controlled patients, endpoint scores approached 7, indicating little or no impact of asthma on their QOL. However, AQLQ scores of not well-controlled patients also improved substantially in some treatment groups, particularly the SFC group.

These results suggest a relationship between the achievement of guideline-based asthma control and improvements in quality of life to levels where there is little or no impact of asthma on quality of life. Guideline-based asthma control is therefore beneficial to the patient and should be tested in prospective studies.
\end{abstract}

Eur Respir J 2002; 20: 588-595.

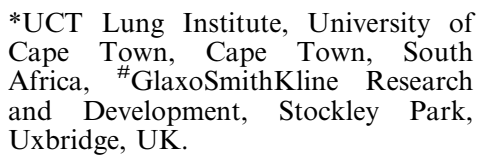

Correspondence: E.D. Bateman

UCT Lung Institute

PO Box 34560

Groote Schuur 7937

Cape Town

South Africa

Fax: 27214066902

E-mail: ebateman@uctgsh1.uct.ac.za

Keywords: Asthma control

budesonide

fluticasone propionate

practice guidelines

quality of life

salmeterol

Received: November 132001

Accepted after revision: March 42002
The aim of asthma management is to achieve control of the disease. National and international management guidelines define asthma control according to a set of treatment goals based on asthma symptoms, rescue $\beta_{2}$-agonist use, exacerbations, objective measures of lung function, activity limitation and adverse effects of medication. The achievement of all of these goals should be regarded as constituting asthma control [1-3].

It has recently been shown that overall asthma control can be achieved with appropriate treatment [4], by fulfilling the asthma treatment goals recommended in the Global Initiative for Asthma (GINA) guidelines [3]. However, although a guideline-based definition of control is much broader than a definition that uses a single clinical measure, such as peak expiratory flow (PEF) or symptom scores, it still defines control primarily from the doctor's perspective, in terms of clinical indices, rather than the impact on the patient's quality of life. It has been shown that patient-perceived benefits cannot be inferred from conventional clinical measures [5]. Therefore, it should not be assumed that meeting the GINA treatment goals, which are based primarily on clinical indices, will necessarily be meaningful to patients. The patient's perspective of how successfully their asthma is being treated is not yet addressed in the goals of treatment guidelines, but is better represented by measures of quality of life (QOL), such as the Asthma Quality of Life Questionnaire (AQLQ), than by physiological endpoints such as lung function, as measured by spirometry. Furthermore, it is worth noting that the emphasis of previous studies of QOL in asthma has been on how much it improves rather than whether it reaches an optimal or maximal level.

Three clinical studies have been reported [6-8] that used the AQLQ to measure the effect of the salmeterol/fluticasone propionate combination product (SFC; Seretide $^{\mathrm{TM}} /$ Advair $^{\mathrm{TM}} / \mathrm{Viani}^{\mathrm{TM}}$, all GlaxoSmithKline, Uxbridge, UK) on QOL, and thus were selected for this retrospective analysis. The aim was to explore the association between the achievement of asthma control, measured according to criteria from the widely-accepted GINA guidelines, and QOL, measured with the AQLQ. In particular, the present authors sought to determine whether maximal or near-maximal AQLQ scores, representing minimal or no impact of asthma on QOL, are attainable. This 
may in turn generate formal hypotheses that can then be prospectively tested.

\section{Methods}

\section{Studies and population}

This was a retrospective analysis of data from all of the controlled clinical trials that investigated the clinical efficacy of SFC and its effect on QOL in patients with persistent asthma. The methods for these three comparative, randomised, double-blind, parallelgroup studies, together with the results of the clinical efficacy protocols, have been published in detail previously [9-11]. In studies A [9] and B [10], SFC (50/100 and 50/250 $\mu \mathrm{g}$, respectively) was compared with fluticasone propionate (FP; 100 and $250 \mu \mathrm{g}$, respectively), salmeterol $50 \mu \mathrm{g}$ and placebo, all of which were given twice daily. In study C [11], the SFC dosage was $50 / 250 \mu \mathrm{g}$ twice daily and the comparator product was budesonide, $800 \mu \mathrm{g}$ twice daily. In study $\mathrm{C}$, QOL was assessed in a subset of patients from four of the 10 countries in which the clinical trial was performed. A total of 1,058 patients, $\geqslant 12$ yrs-of-age, were randomised into these three clinical studies. The details of the inclusion criteria for each study and the numbers of patients in each treatment group are shown in table 1 . These studies included patients with differing severities of asthma. In particular, the patients in study A had less severe asthma than those in study B. All drugs were administered twice daily for either 12 weeks (studies A and B) or 24 weeks (study C) via a Diskus ${ }^{\mathrm{TM}}$ dry powder inhaler, except for budesonide, which was delivered via a Turbuhaler ${ }^{\mathrm{TM}}$. The results of the QOL analyses have also been reported separately [6-8].

\section{Assessing asthma control}

Data were collected in a broadly similar manner across all studies, from either patient diary cards (daytime and night-time symptom scores, use of rescue short-acting $\beta_{2}$-agonists and morning peak expiratory flow) or case record forms (exacerbations, adverse drug reactions).

The definition of asthma control used in this analysis was derived from the goals of long-term asthma management identified in the GINA guidelines [3]. Patients in the three studies were classified as either "well controlled" or "not well controlled" according to the level of asthma control achieved during an 8-week period of the study (weeks 5-12 post-randomisation). The criteria used to assess patients in this analysis are summarised together with the GINA criteria in table 2. In order to convert the qualitative GINA goals into quantitative measures, pragmatic assumptions based on usual clinical practice were employed. For example, "Minimal need for quick-relief $\beta_{2}$-agonist therapy" was interpreted as the use of a rescue bronchodilator on no more than 2 days in a week, and a total weekly use of no more than 4 occasions (or 8 puffs).

The evaluation period for this retrospective analysis was the same in all three studies: weeks 5-12 postrandomisation. This period was selected to ensure that the analysis was performed during the period of maximum (plateau) effect for all study treatments, and to avoid bias in favour of the groups that received bronchodilators (alone or in combination), which would be expected to take effect more quickly than inhaled corticosteroids.

Certain thresholds were set for control assessments to determine whether a patient could be included in the retrospective analysis. If any of these thresholds were not met, data from that patient was classed as

Table 1. - Studies included in the analysis

\begin{tabular}{|c|c|c|c|c|c|c|}
\hline \multirow[t]{2}{*}{ Study } & \multirow[t]{2}{*}{ [Ref no.] } & \multirow{2}{*}{$\begin{array}{l}\text { Study } \\
\text { duration } \\
\text { weeks }\end{array}$} & \multicolumn{3}{|c|}{ Inclusion criteria } & \multirow{2}{*}{$\begin{array}{l}\text { Treatments tested } \\
\text { (all administered } \\
\text { twice daily) (n) }\end{array}$} \\
\hline & & & $\begin{array}{l}\text { Symptoms/rescue } \\
\text { medication }\end{array}$ & $\mathrm{FEV} 1 / \mathrm{PEF}$ & $\begin{array}{l}\text { Previous treatment } \\
\text { (dose per day) }\end{array}$ & \\
\hline A & [9] & 12 & $\begin{array}{l}\text { During 2-week } \\
\text { run-in: } \leqslant 3 \text { days } \\
\text { with } \geqslant 12^{4} \text { puffs } \\
\text { bronchodilator; } \\
\text { during last } 7\end{array}$ & $\begin{array}{l}\text { FEV } 140-85 \% \\
\text { pred }\end{array}$ & $\begin{array}{l}\text { BDP } 300-500 \mu \mathrm{g} \\
\text { FLU } 1000 \mu \mathrm{g} \\
\text { FP } 200 \mu \mathrm{g} \\
\text { Salm. } 100 \mu \mathrm{g} \\
\text { TCA } 600-1000 \mu \mathrm{g}\end{array}$ & $\begin{array}{l}\text { SFC 50/100 } \mu \mathrm{g}(92) \\
\text { Salm. } 50 \mu \mathrm{g}(92) \\
\text { FP } 100 \mu \mathrm{g}(90) \\
\text { PL (82) }\end{array}$ \\
\hline B & [10] & 12 & $\begin{array}{l}\text { days of run-in: } \\
\leqslant 3 \text { nights with } \\
\text { rescue } \\
\text { bronchodilator }\end{array}$ & & $\begin{array}{l}\text { BDP } 550-800 \mu \mathrm{g} \\
\text { FLU } 1250-2000 \mu \mathrm{g} \\
\text { FP } 500 \mu \mathrm{g} \\
\text { TCA } 1100-1600 \mu \mathrm{g}\end{array}$ & $\begin{array}{l}\text { SFC } 50 / 250 \mu \mathrm{g}(84) \\
\text { Salm. } 50 \mu \mathrm{g}(88) \\
\text { FP } 250 \mu \mathrm{g}(84) \\
\text { PL (93) }\end{array}$ \\
\hline $\mathrm{C}$ & {$[11]^{\#}$} & 24 & $\begin{array}{l}\text { During week } \\
\text { before } \\
\text { randomisation: } \\
\text { total day+night } \\
\text { symptom score } \\
\geqslant 2 \text { on } \geqslant 4 \text { days }\end{array}$ & $\begin{array}{l}\text { FEV1 or PEF } \\
50-85 \% \text { pred }\end{array}$ & $\begin{array}{l}\text { BUD } 800-1200 \mu \mathrm{g} \\
\text { BDP } 800-1200 \mu \mathrm{g} \\
\text { FP } 400-600 \mu \mathrm{g}\end{array}$ & $\begin{array}{l}\text { SFC 50/250 } \mu \mathrm{g}(180) \\
\text { BUD } 800 \mu \mathrm{g}(173)\end{array}$ \\
\hline
\end{tabular}

BDP: beclomethasone dipropionate; BUD: budesonide; FLU: flunisolide; FEV1: forced expiratory volume in one second; FP: fluticasone propionate; PEF: peak expiratory flow; PL: placebo; \% pred: \% predicted; Salm.: salmeterol; SFC: salmeterol/ fluticasone propionate combination; TCA: triamcinolone acetonide. ${ }^{\uparrow}$ : For patients previously on inhaled corticosteroids; $\geqslant 6$ puffs for those on Salm. \#: Quality-of-life analysis only performed in 4 of the 10 participating countries. 
Table 2.-Definitions of asthma control

\begin{tabular}{|c|c|}
\hline $\begin{array}{l}\text { Long-term asthma management goals } \\
\text { (GINA guidelines) [3] }\end{array}$ & $\begin{array}{l}\text { Definition of successful control used in the } \\
\left.\text { present analysis (each week }{ }^{\#}\right)\end{array}$ \\
\hline Minimal or no symptoms, including night-time symptoms & No night-time waking due to asthma \\
\hline Minimal asthma episodes or attacks & No emergency hospital visits \\
\hline No emergency visits to doctors or hospitals & No exacerbations \\
\hline $\begin{array}{l}\text { Minimal need for quick-relief } \\
\beta_{2} \text {-agonist therapy }\end{array}$ & $\begin{array}{l}\text { No treatment-related adverse effects causing } \\
\text { a change in asthma therapy }\end{array}$ \\
\hline No limitations on physical activities and exercise & Plus at least two of the following: \\
\hline Nearly normal lung function & No more than 2 days when symptom score is $>1$ \\
\hline Minimal or no side-effects from medication & $\begin{array}{l}\text { Rescue bronchodilator used on } \leqslant 2 \text { days and } \\
\text { total weekly use } \leqslant 4 \text { occasions ( } 8 \text { puffs) } \\
\text { Morning PEF } \geqslant 80 \% \text { predicted }\end{array}$ \\
\hline
\end{tabular}

PEF: peak expiratory flow; \% pred: \% predicted; GINA: Global Initiative for Asthma Guidelines. ${ }^{\text {: }}$ Patients were classed as well controlled for the 8-week evaluation period if they had $\geqslant 4$ weeks evaluable data and were well controlled on every evaluable week, or were well controlled for 6 out of 7 , or 7 out of 8 weeks (see text).

missing. For each week, a qualifying criterion could only be assessed if the data were available for $\geqslant 5$ of the 7 days. The level of control in any given week could only be assessed if all the individual criteria for that week were evaluable. One exception to this was that if one of the group of three criteria $(\mathrm{PEF}$, symptoms and rescue salbutamol use) was not evaluable, the patient could still be classified as well controlled, as long as there were sufficient data to show that the other two criteria had been met (as a patient could fail one of these three criteria in a week and still be classed as well controlled).

Control could only be evaluated if data from a patient were available for $\geqslant 4$ of the 8 weeks in question. To be classed as well controlled, patients had to be well controlled in every evaluable week, that is: 4 out of 4 weeks, 5 out of 5, 6 out of 6,7 out of 7, or 8 out of 8 . Where $\geqslant 7$ weeks of evaluable data were available, a patient could still be classed as well controlled if they achieved control for 6 out of 7 or 7 out of 8 weeks. Patients with 4 weeks of evaluable data who failed to achieve one of these targets were classed as not well controlled. Furthermore, if patients withdrew from the study because of an asthma exacerbation or a drug-related adverse event, or if the study treatment lacked efficacy, they were classed as not well controlled for the whole 8-week period. Data from patients who withdrew for any other reason were classed as missing.

\section{Quality of life assessment}

The QOL measure used in these three studies was the self-administered version of the AQLQ. The AQLQ is a disease-specific instrument that has been validated in clinical trials [12-15]. The AQLQ contains 32 questions (items) comprising four domains: Activity Limitations, Asthma Symptoms, Emotional Function and Environmental Exposure. Each item is scored on a 7-point Likert scale where 1 indicates severe impairment and 7 indicates no impairment. The overall score is the mean of the 32 items. A change in mean overall or domain score of 0.5 has been shown to represent the smallest change of importance to the patient (the "minimal important difference"), and a change in score of 1.0 represents a moderate change [16]. The AQLQ is a disease-specific questionnaire, so it would not be meaningful to test it in a healthy population in an attempt to define the AQLQ score for a nonasthmatic. However, a maximum overall AQLQ score (7) represents no impairment in QOL due to asthma, and scores approaching 7 imply a minimal impact of asthma on QOL.

\section{Statistical analysis}

Data were analysed to determine control status over the 8-week period and mean overall AQLQ scores at study baseline and endpoint (either the end of the treatment period or upon early withdrawal) for each evaluable patient. No missing data were imputed. To examine whether the exclusion of patients for whom control was unevaluable due to missing data affected the results, these patients were included in a repeat analysis using the conservative assumption that they were not well controlled.

This analysis was retrospective and no hypothesis was established prior to analysis so only descriptive summary statistics are presented. The mean and SD of the AQLQ scores at study endpoint and the difference between endpoint and baseline scores were determined for the well-controlled and not well-controlled subgroups of each treatment group.

An additional analysis was conducted on the data from study A to compare the composite definition of control, based on GINA guidelines, with control measured by four of the individual clinical parameters that constitute the composite measure of asthma control. The aim was to see whether control of any one parameter was associated with the overall QOL improvement obtained when composite asthma control was achieved. Based on the present authors' previous paper [4], the individual criteria selected were PEF, day- and night-time symptom scores and $\beta_{2}$-agonist use, as failure to satisfy one or more of these criteria was the most common reason for not achieving overall control (as defined by a composite measure). 


\section{Results}

The numbers of patients in studies $\mathrm{A}, \mathrm{B}$ and $\mathrm{C}$ who provided sufficient data to be evaluable in at least one analysis were 306, 313 and 114, respectively. The majority of patients excluded were those that failed to complete the AQLQ adequately. The distribution of patients between the treatment groups was generally even.

\section{Overall Asthma Quality of Life Questionnaire score at endpoint}

The mean overall AQLQ scores at endpoint for well-controlled and not well-controlled patients are presented in figure 1. Well-controlled patients who achieved guideline-based asthma control had consistently higher overall AQLQ scores than the patients who were not well controlled. Mean AQLQ scores achieved by well-controlled patients at endpoint were largely similar, regardless of treatment intervention or asthma severity, and, with the exception of the budesonide group in study $\mathrm{C}$, approached or exceeded 6 . While mean AQLQ scores were similar across treatment groups in well-controlled patients, the number of patients who achieved well-controlled status varied markedly by treatment intervention. The greatest number of well-controlled patients was seen in the SFC group in all three studies, with only a few wellcontrolled patients in the placebo (studies A and B) and budesonide (study $\mathrm{C}$ ) treatment groups.

In patients who were not well controlled, mean overall AQLQ scores were lower than for controlled patients and the AQLQ score achieved at endpoint was dependent on the treatment used. A consistent trend was seen in the ranking of overall AQLQ scores by treatment group in studies $\mathrm{A}$ and $\mathrm{B}$, i.e. $\mathrm{SFC}>\mathrm{FP}>$ salmeterol>placebo (fig. 1).

Change from baseline in Asthma Quality of Life Questionnaire score

The mean changes in AQLQ scores (from baseline at endpoint) for well-controlled and not wellcontrolled patients are presented in table 3 . The trends were similar to those seen for overall endpoint scores: well-controlled patients achieved greater improvements in AQLQ than not well-controlled patients. In the majority of cases, the mean changes exceeded the threshold for minimal important difference $(\geqslant 0.5)$. This difference was seen consistently within each treatment group in all studies (with the exception of budesonide in study $\mathrm{C}$ ).

As with the overall endpoint AQLQ scores, mean change in AQLQ in the not well-controlled patients was dependent on the treatment group, and the same ranking of score changes was seen: $\mathrm{SFC}>\mathrm{FP}>$ salmeterol $>$ placebo for studies A and B. The only patients who recorded clinically important gains irrespective of level of control were those who received SFC. As with the analysis of overall score, the number of patients
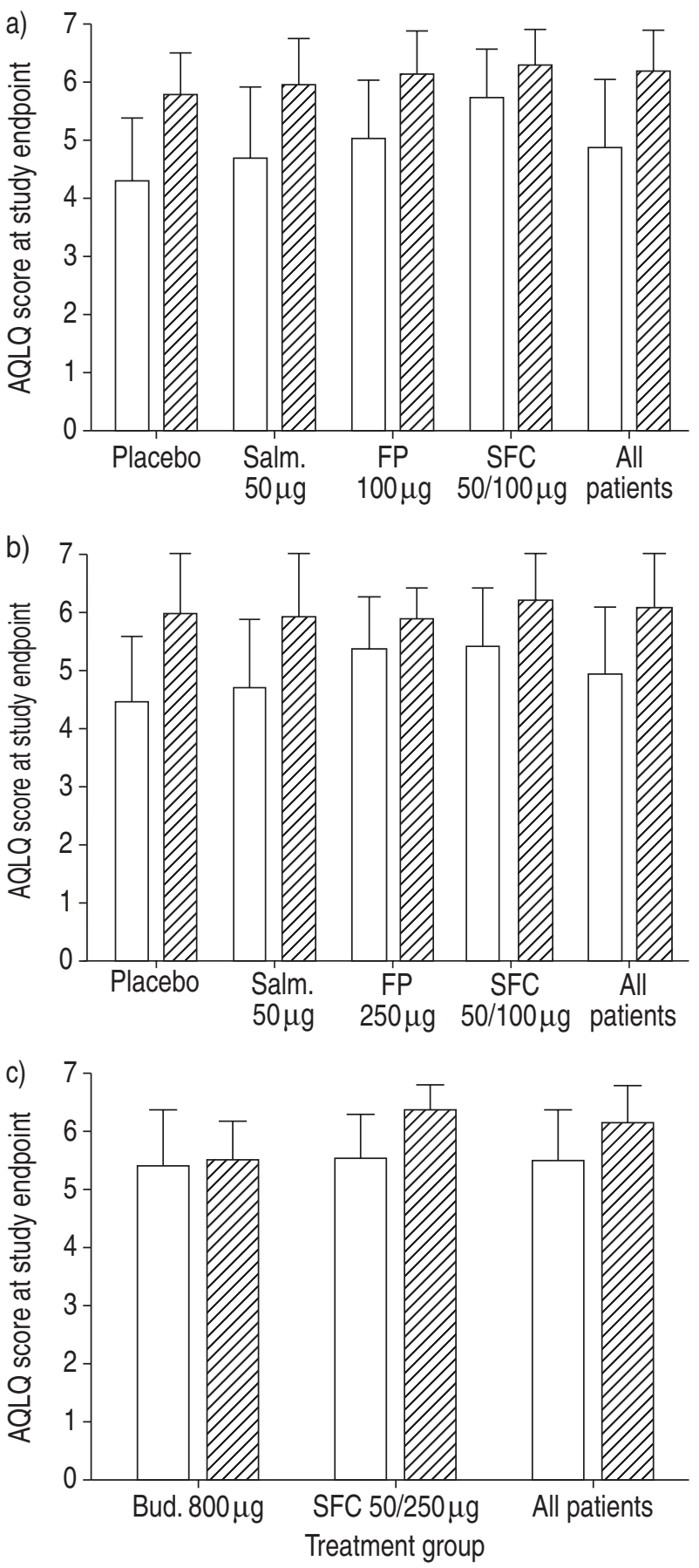

Fig. 1.-Overall Asthma Quality of Life Questionnaire (AQLQ) scores ( $\square$ : not well controlled (NWC); $\mathbb{Z}$ : well controlled (WC)) at study endpoint for patients in studies a) A, b) B and c) C. Mean scores (bars) and standard deviation (lines) shown for all patients and by treatment group. All dosages shown were given twice daily. Bud.: budesonide; FP: fluticasone propionate; Salm.: salmeterol; SFC: salmeterol/fluticasone propionate combination. The number of patients were as follows (treatment group, NWC and WC). Study A: placebo, 58 and 4; Salm., 69 and 13; FP, 54 and 24; SFC, 35 and 49; all patients, 216 and 90 . Study B: placebo, 74 and 8; Salm., 65 and 12; FP, 53 and 24; SFC, 38 and 39; all patients, 230 and 83. Study C: Bud., 55 and 5; SFC, 42 and 12; all patients, 97 and 17.

who achieved control differed between the various treatment groups.

The association between asthma control and the 
Table 3. - Change in overall Asthma Quality of Life Questionnaire (AQLQ) scores (from baseline to study endpoint) for patients in studies A, B and C, analysed by treatment group and level of control

\begin{tabular}{|c|c|c|c|c|c|c|}
\hline & \multicolumn{2}{|c|}{ Study A } & \multicolumn{2}{|c|}{ Study B } & \multicolumn{2}{|c|}{ Study C } \\
\hline & Well controlled & $\begin{array}{l}\text { Not well } \\
\text { controlled }\end{array}$ & Well controlled & $\begin{array}{l}\text { Not well } \\
\text { controlled }\end{array}$ & Well controlled & $\begin{array}{l}\text { Not well } \\
\text { controlled }\end{array}$ \\
\hline Place & $0.24 \pm 0.47$ (4) & $-0.40 \pm 0.93(57)$ & $0.57 \pm 1.38(8)$ & $-0.37 \pm$ & & \\
\hline Salmeterol & $0.64 \pm 0.58(13)$ & $-0.22 \pm 1.13(69)$ & $1.19 \pm 0.89$ (12) & $-0.35 \pm 1.14(64)$ & & \\
\hline FP & $0.99 \pm 1.08(23)$ & $0.41 \pm 1.04(54)$ & $0.68 \pm 0.66(24)$ & $0.50 \pm 0.87(53)$ & & \\
\hline SFC & $1.11 \pm 0.82(49)$ & $0.92 \pm 0.87(35)$ & $1.14 \pm 1.08$ & $0.88 \pm 1.14(38)$ & $0.99 \pm 0.69$ & $0.98 \pm 0.90$ \\
\hline Budesonide & & & & & $0.02 \pm 0.52$ & $0.50 \pm 0.98$ \\
\hline All patients & $0.97 \pm 0.87(89)$ & $0.08 \pm 1.12(215)$ & $0.96 \pm 1.00(83)$ & $0.05 \pm 1.22(227)$ & $0.80 \pm 0.76(15)$ & $0.72 \pm 0.97(77)$ \\
\hline
\end{tabular}

Data are presented as score change, mean \pm SD (n). FP: fluticasone propionate; SFC: salmeterol/fluticasone propionate combination.

change in QOL during each study is further illustrated by examining the number of patients who achieved a clinically important improvement in QOL. The result of this analysis for study A are presented in figure 2. This shows that the group of patients who achieved an AQLQ score change of $\geqslant 0.5$ contained a higher number of well-controlled patients than the group who failed to achieve this score change, and that substantially more patients in the SFC group (whether or not they were well controlled) achieved this change in score than in the other treatment groups. The results from studies $\mathrm{B}$ and $\mathrm{C}$ show a similar trend (data not shown).

The relationships between baseline and endpoint AQLQ scores for all patients in studies A and B were assessed, for each treatment group and by level of control, by plotting the two values on a scatter plot (fig. 3). The well-controlled patients showed improvements in AQLQ score, many to near-maximal levels. In addition, the plots for well-controlled patients also show that near-maximal endpoint AQLQ scores were achieved in patients with a range of baseline scores, in some cases as low as 3-4. By contrast, the not wellcontrolled subgroups contained a higher proportion

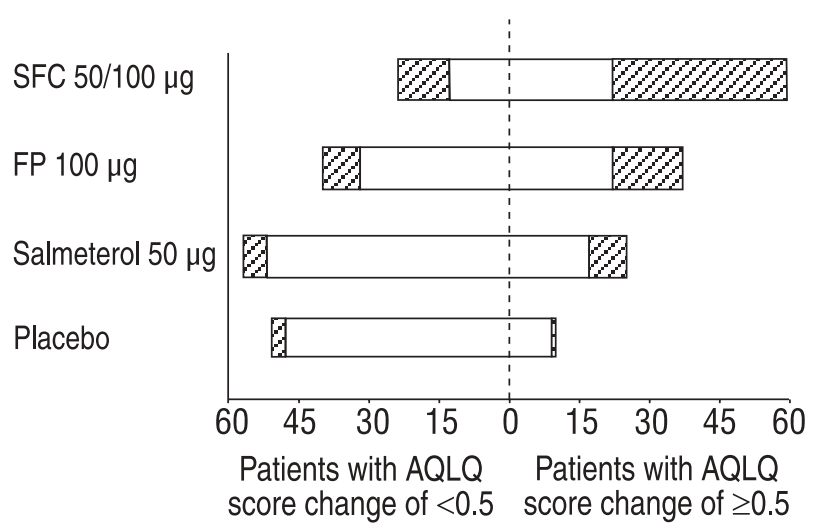

Fig. 2.-Number of patients in study A (by treatment group) who achieved a clinically important change $(\geqslant 0.5)$ in Asthma Quality of Life Questionnaire (AQLQ) score, analysed by level of control. $\square$ : not well controlled; $\mathbb{Z}$ : well controlled. All doses shown were given twice daily. FP: fluticasone propionate; SFC: salmeterol/ fluticasone propionate combination. of patients whose endpoint scores were the same as, or less than, their baseline scores.

Based on the aforementioned results, study A was selected for the subanalysis (as it provided more wellcontrolled patients than the other two studies) to examine the relationship between change in AQLQ score from baseline and achievement of control according to the composite measure and four single clinical measures (table 4). Using the composite measure of control, the difference in AQLQ score changes between well-controlled and not well-controlled patients was relatively large $(0.89)$. In contrast, when control was assessed according to a single clinical measure, the difference in AQLQ score change between those who achieved control and those who did not was smaller $(0.17-0.53)$.

\section{Discussion}

Retrospective analysis of three clinical studies supports the hypothesis that asthma control, as defined by physician-based criteria in asthma management guidelines, is associated with improved QOL as assessed by the patient. Furthermore, these data suggest that well-controlled patients can achieve near-maximal AQLQ scores, representing little or no impact of asthma on their lives. This hypothesis should be prospectively tested in future studies.

The apparent association between the achievement of guideline-based asthma control and better QOL is shown by mean AQLQ scores at study endpoints that are higher in the well-controlled patient subgroups. This was seen consistently across studies, and therefore severities of asthma, suggesting that even in more severe patients, the same asthma control objectives are achievable and that patients with more severe disease do not have to accept less favourable outcomes. The improvement in AQLQ score from baseline at endpoint also appears to be greater in well-controlled than not well-controlled patients, which was seen consistently within each treatment group. In the majority of cases, the improvements in QOL in the well-controlled group exceeded the threshold for a clinically important difference. The present authors also found that patients who recorded low baseline 

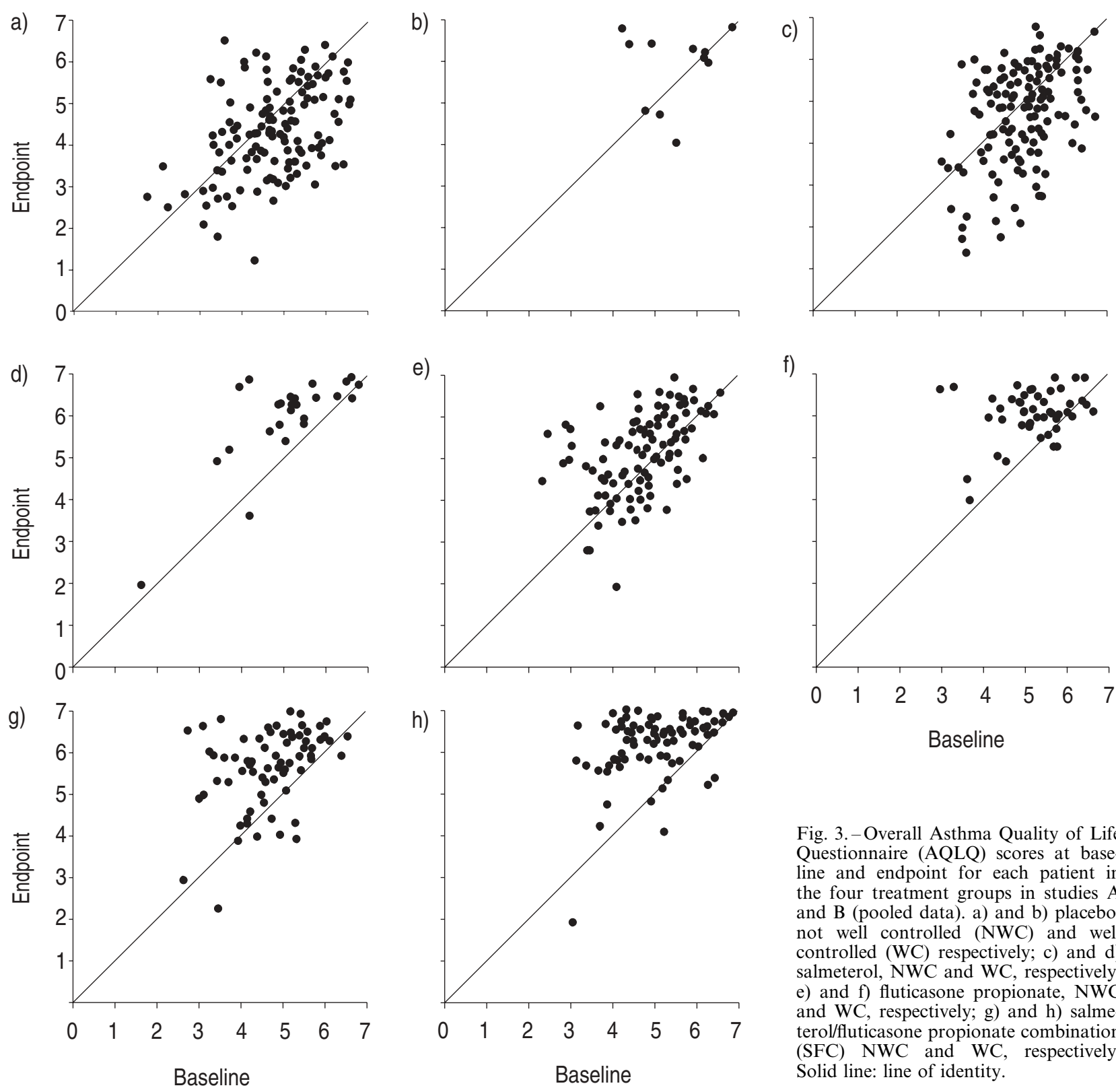

Fig. 3.-Overall Asthma Quality of Life
Questionnaire (AQLQ) scores at base-
line and endpoint for each patient in
the four treatment groups in studies A
and B (pooled data). a) and b) placebo,
not well controlled (NWC) and well
controlled (WC) respectively; c) and d)
salmeterol, NWC and WC, respectively;
e) and f) fluticasone propionate, NWC
and WC, respectively; g) and h) salme-
terol/fluticasone propionate combination
(SFC) NWC and WC, respectively.
Solid line: line of identity.

AQLQ scores were more likely to achieve higher, and in some cases near-maximal, endpoint scores if they were well controlled, than those patients who were not well controlled.

While well-controlled patients achieved greater improvements in QOL than not well-controlled patients, some differences were observed between treatment groups. Patients who received SFC experienced clinically important improvements in QOL whether or not they were well controlled. This was evident in both the change in AQLQ score and in the number of patients achieving a clinically meaningful improvement in AQLQ, compared with other treatments. This suggests that even if control is not achieved, meaningful improvements in QOL can be obtained with appropriate treatment.
The composite definition of control used in this analysis had six components, including measures of disease that would be perceived as important by patients, such as symptom score, bronchodilator usage, night-time waking and exacerbations. Therefore, at first sight it might be expected that patients who achieve control of their asthma in several ways should experience accompanying benefits in their QOL. However, the definition of control is based on clinical indices and the QOL assessment is based on a patient's perception of benefit. It would be wrong to assume that meeting the needs of the clinician is the same as meeting the needs of the patient. Indeed, it has been shown that no single conventional clinical measure can capture patient-perceived QOL benefits [5]. 
Table 4. - Changes in overall Asthma Quality of Life Questionnaire (AQLQ) scores (from baseline to study endpoint) for patients in study A (all treatments combined). Comparison between composite definition of asthma control and control measured according to a single parameter

\begin{tabular}{|c|c|c|c|}
\hline & \multicolumn{2}{|c|}{ AQLQ score change } & \multirow[t]{2}{*}{ Difference mean $\pm \mathrm{SE}$} \\
\hline & Well controlled & Not well controlled & \\
\hline Composite control measure & $0.97 \pm 0.87$ & $0.08 \pm 1.12$ & $0.89 \pm 0.13$ \\
\hline \multicolumn{4}{|l|}{ Single control measures: } \\
\hline Peak expiratory flow & $0.87 \pm 1.05$ & $0.43 \pm 0.90$ & $0.44 \pm 0.12$ \\
\hline Night-time symptoms & $0.66 \pm 0.99$ & $0.49 \pm 0.99$ & $0.17 \pm 0.15$ \\
\hline Daytime symptoms & $0.87 \pm 0.93$ & $0.34 \pm 0.99$ & $0.53 \pm 0.12$ \\
\hline Rescue $\beta_{2}$-agonist use & $0.84 \pm 0.99$ & $0.50 \pm 0.98$ & $0.34 \pm 0.13$ \\
\hline
\end{tabular}

Data are presented as mean \pm SD unless otherwise stated. SE: standard error; SD: standard deviation.

The results of the present analysis are consistent with other published data in so far as they suggest that if a patient's asthma control improves, their AQLQ scores increase $[17,18]$. However, the present analysis is different, and therefore valuable, in two key aspects: the focus on maximum attainable AQLQ at endpoint rather than the change from baseline, and the definition of asthma control used, which was based on the goals of the GINA guidelines.

The emphasis of the present analysis was not only on improvement in QOL from baseline, but also the attainment of maximal or near-maximal AQLQ scores, suggesting minimal or no impact of asthma on QOL. Although the current study is a retrospective analysis, the variety of analyses that have been performed provides useful information on the relationship between these two approaches to assessing QOL. More importantly, it supports the view that physicians and patients do not appreciate the extent to which asthma can be completely controlled and patients can enjoy normal QOL. This relationship, and the assessment of the proportion of asthmatics in which ideal control can be achieved, will require study in prospective trials.

The second key aspect of this analysis was the definition of asthma control used. Asthma control was defined using a composite measure that corresponds to the long-term management goals set out by established international treatment guidelines. This analysis therefore attempts to validate the long-term treatment goals of GINA from the patients' perspective. This approach appears to be justified, in that it was shown that there are differences in the degrees of QOL improvement according to whether asthma control is defined using a composite measure or a single measure, such as PEF. The results of this analysis suggest that if patients achieve guidelinebased composite control, they will achieve larger improvements in QOL than if success in only a single measure is achieved. Conversely, failure to achieve good control as measured by a single parameter does not necessarily predict failure in terms of QOL improvements. This supports the view that a composite control measure provides a better predictor of likely improvement in quality of life or of likely failure to improve than measurement of single clinical endpoints.

An additional important feature of the control definition employed in the present study was that patients were assessed over an 8-week period, during which their asthma was evaluated weekly according to goals set out in the GINA guidelines [3]. Some groups have proposed that control should be assessed over shorter periods than 1 week; an example of such a measure is the "asthma control day" [19, 20]. However, measuring control over a longer time period than 1 day should give a better picture of how well a patient can both achieve and maintain control. The assessment of longitudinal control with a daily measure is more difficult because a patient's level of control can vary considerably from one day to the next, generating greater variability in the data. The decision to use weekly control assessments corresponds more closely to the management goals in the GINA guidelines than measuring control daily, which is the method used in the present authors' previous paper [4]. Moreover, from the physician's point of view, a week is a more practical period over which to evaluate asthma control. This is an important consideration, as any assessment of control must be practical or usable in clinical practice.

The proportion of patients in the three studies who achieved well-controlled status varied considerably by treatment group, but overall was low $(26 \%)$. It should be noted, however, that within the trials analysed, treatment interventions were fixed and were not titrated to achieve either optimal control or optimal QOL for each patient. The statistical design chosen was a simple re-analysis that generated summary statistics only. The decision not to include comparative statistics seems justified by the unequal sizes of the subgroups that arose from the analysis. This inequality in subgroup sizes arose because several patients from the original study databases provided insufficient data for analysis of asthma control, and so were excluded from the datasets. To examine whether the allocation of missing data affected the results of the analysis, this analysis was repeated using the very conservative assumption that all patients who were unevaluable due to missing data were not well controlled. The overall findings of this re-analysis were identical to those of the primary analyses, although the AQLQ scores in the not well-controlled groups were marginally lower.

In conclusion, the present analysis suggests that in patients with persistent asthma, the achievement of 
asthma control (as defined by physician-based, clinical criteria in treatment guidelines) is associated with greater improvements in quality of life, reaching nearmaximal levels, and is therefore of benefit to the patient. In addition, these improvements appear to be achievable in patients with low baseline Asthma Quality of Life Questionnaire scores and with a range of disease severity, suggesting that even in patients with more severe asthma, treatment goals should be the same as those with less severe asthma. However, in patients who do not achieve control, considerable improvements in quality of life may still be gained with appropriate therapy, in this analysis combination therapy with salmeterol and fluticasone propionate. These findings should be further investigated in prospective studies.

\footnotetext{
Acknowledgements. This study was sponsored by GlaxoSmithKline plc. The authors would like to acknowledge the valuable contribution of N. Gul, M. Ho, M. Price and S. Sondhi of GlaxoSmithKline plc.
}

\section{References}

1. British Thoracic Society. The British guidelines on asthma management 1995 review and position statement. Thorax 1997; 52: Suppl. 1, S1-S21.

2. National Asthma Education and Prevention Program. Guidelines for the diagnosis and management of asthma. Expert panel report 2. Publication number 97-4051. Bethesda, National Institutes of Health, National Heart, Lung and Blood Institute, 1997.

3. National Institutes of Health. Global Initiative for Asthma: pocket guide for asthma management and prevention. Publication No. 95-3659B. Bethesda, National Institutes of Health, National Heart Lung and Blood Institute, 1998.

4. Bateman ED, Bousquet $\mathbf{J}$, Braunstein GL. Is overall asthma control being achieved? A hypothesisgenerating study. Eur Respir J 2001; 17: 589-595.

5. Juniper EF, Svensson K, O'Byrne PM, et al. Asthma quality of life during 1 year of treatment with budesonide with or without formoterol. Eur Respir J 1999; 14: 1038-1043.

6. Juniper EF, Jenkins C, Price MJ, Thwaites RMA, James M. Quality of life of asthma patients treated with salmeterol/fluticasone propionate combination product and budesonide (abstract). Eur Respir $J$ 1999; 14: Suppl. 30, 370s.

7. Reese PR, Mahajan P, Woodring A. Salmeterol/ fluticasone propionate combination product improves quality of life in asthma patients (abstract). Eur Respir J 1998; 12: Suppl. 28, 35s.

8. Reese PR, Mather DB, Mahajan P, Woodring A. Combination of salmeterol/fluticasone propionate via Diskus improves quality of life in asthma patients (abstract). J Allergy Clin Immunol 1999; 103: s69.

9. Kavuru M, Melamed J, Gross G, et al. Salmeterol and fluticasone propionate combined in a new powder inhalation device for the treatment of asthma: a randomized, double-blind, placebo-controlled trial. J Allergy Clin Immunol 2000; 105: 1108-1116.

10. Shapiro G, Lumry W, Wolfe J, et al. Combined salmeterol $50 \mu \mathrm{g}$ and fluticasone propionate $250 \mu \mathrm{g}$ in the Diskus device for the treatment of asthma. Am J Respir Crit Care Med 2000; 161: 527-534.

11. Jenkins C, Woolcock AJ, Saarelainen P, Lundbäck B, James MH. Salmeterol/fluticasone propionate combination therapy $50 / 250 \mu \mathrm{g}$ twice daily is more effective than budesonide $800 \mu \mathrm{g}$ twice daily in treating moderate to severe asthma. Respir Med 2000; 94: 715723.

12. Juniper EF, Guyatt GH, Ferrie PJ, Griffith LE. Measuring quality of life in asthma. Am Rev Respir Dis 1993; 147: 832-838.

13. Rutten-van Mölken MPMH, Custers F, Van Doorslaer EKA, et al. Comparison of performance of four instruments in evaluating the effects of salmeterol on asthma quality of life. Eur Respir $J$ 1995; 8: 888-898.

14. Leidy NK, Coughlin C. Psychometric performance of the Asthma Quality of Life Questionnaire in a US sample. Qual Life Res 1998; 7: 127-134.

15. Rowe BH, Oxman AD. Performance of an asthma quality of life questionnaire in an outpatient setting. Am Rev Respir Dis 1993; 148: 675-681.

16. Juniper EF, Guyatt GH, William A, Griffith LE. Determining a minimal important change in a disease-specific quality of life questionnaire. $J$ Clin Epidemiol 1994; 47: 81-87.

17. Vollmer WM, Markson LE, $\mathrm{O}^{\prime}$ Connor E, et al. Association of asthma control with health care utilization and quality of life. Am J Respir Crit Care Med 1999; 160: 1647-1652.

18. Juniper EF, O'Byrne PM, Ferrie PJ, King DR, Roberts JN. Measuring asthma control: clinic questionnaire or daily diary? Am J Respir Crit Care Med 2000; 162: 1330-1334.

19. Zetterström O, Buhl R, Mellem H, et al. Improved asthma control with budesonide/formoterol in a single inhaler, compared with budesonide alone. Eur Respir J 2001; 18: 262-268.

20. Malmstrom K, Rodriguez Gomez G, Guerra J, et al. Oral montelukast, inhaled beclomethasone, and placebo for chronic asthma: randomized, controlled trial. Ann Intern Med 1999; 130: 487-495. 